\title{
Professores, Mestres e Educadores: a Docência aos Olhos do Jornal O Repórter (Uberlândia-MG: 1950-1970)
}

\section{Teachers, Masters and Educators: the teaching in the eyes of the O Repórter Newspaper (Uberlândia-MG: 1950-970)}

Sauloéber Tarsio de Souza

Orcid: https://orcid.org/0000-0002-9797-341X

Universidade Federal de Uberlândia,

INHIS/PPGED/ProfHistoria, Brasil,

sauloeber@gmail.com

\author{
José Lito Salustriano da Silva \\ Orcid: https://orcid.org/0000-0002-9345-4372 \\ Universidade Federal de Uberlândia, \\ ICHPO, Brasil, \\ josearmando12244@gmail.com
}

DOI: 10.21680/2596-0113.2021v4nOID23974

Citation: Souza, S. T. de. \& Silva, J. L. S. da. (2021). Professores, Mestres e Educadores: a Docência aos Olhos do Jornal O Repórter

(Uberlândia-MG: 1950-1970). History of

Education in Latin America - HistELA, 4, e23974.

Competing interests: The authors have declared that no competing interests exist.

Editor: Olivia Morais de Medeiros Neta

Received: 03/02/2021

Approved: 28/04/2021

\section{OPEN ACCESS}

\begin{abstract}
Resumo
Neste texto, abordamos a ideia de docência veiculada no jornal "O Repórter", tentando identificar o estereótipo de professor(a) que era apresentado aos seus leitores. No processo de coleta das notícias, levantamos 846 matérias relativas a educação na coleção deste jornal constante do acervo do Arquivo Público Municipal de Uberlândia-MG, no período entre 1950 e 1963. A temática debatida em torno da profissão docente foi bastante expressiva com cerca de $10 \%$ do total das reportagens (87 notícias). As reflexões alcançadas indicam que no processo de acelerado crescimento da rede escolar urbana do município mineiro, as representações dos professores eram apresentadas entre dois polos distintos muitas vezes como figuras de prestígio dignas de exaltação, mas também em alguns momentos acusados pela precariedade da educação em função da má formação.
\end{abstract}

Palavras-chave: Representações. Imprensa Escrita. História da Docência. Triângulo Mineiro.

\begin{abstract}
In this text, we approach the idea of teaching published in the newspaper $O$ Repórter, trying to identify the stereotype of teacher that was presented to his readers. In the process of collecting news, we surveyed 846 articles related to education in the collection of this newspaper in the Municipal Public Archive of Uberlândia-MG, between 1950 and 1963. The theme discussed around the teaching profession was quite expressive with $10 \%$ of the total collected (87 reports). The reflections reached indicate that in the process of accelerated growth of the urban school network in that municipality of Minas Gerais, the representations of teachers were presented between two distinct poles, often as prestigious figures worthy of exaltation, but also at times accused by the precariousness of education in function of them precarious formation.
\end{abstract}

Keywords: Representations. Written Press. History of Teaching. Triângulo Mineiro. 


\section{Introdução}

O texto resulta das atividades do projeto "Representações de Imprensa: $O$ Universo Escolar nas Páginas de Jornais do Triângulo Mineiro (1950-1970)", apoiado pela FAPEMIG (Edital 01/2015)i. Os dados apresentados decorrem da catalogação e digitalização das notícias sobre a educação coletadas no Jornal $O$ Repórter que circulava no município de Uberlândia-MG. Desde os anos de 1980, os jornais têm sido amplamente utilizados na pesquisa histórica e também histórico-educativa. Até então, eram considerados fontes suspeitas para esse tipo de pesquisa, pois se entendia que tais veículos de comunicação portavam carga excessiva de interesses subjetivos (Luca, 2006). Nesse texto em específico, abordamos a ideia de docência veiculada pelo Jornal $O$ Repórter, tentando identificar o estereótipo de professor (a) que era apresentado aos leitores do jornal, observando-se também seus sinônimos como os termos mestre e educador.

Esse veículo de impressa escrita surgiu sob a responsabilidade de Artur Barros e J. Faria em 1925 (Uberlândia-MG), no início da década de 1950, circulava duas vezes por semana (aos sábados e as quartas-feiras) em 04 páginas (02 folhas), quando de seu encerramento, no ano de 1963, era veiculado de 3 a 4 vezes por semana e seu presidente diretor era João Deher. Não se sabe ao certo os motivos que levaram o jornal a encerrar suas atividades, porém, o Brasil vivia uma crise econômica no ano de 1963, com inflação crescente (93\% em um ano) colocando em dificuldades o mercado de papel (Bugelli, 2008).

Ao finalizar a primeira etapa do projeto, levantamos um número de 846 matérias relativas à educação na coleção deste jornal constante do acervo do Arquivo Público Municipal de Uberlândia-MG, no período entre 1950 e 1963 com exceção de alguns anos já que os livros de tombo estavam no setor de restauração (1951/52/57/58). Mesmo assim, a temática debatida em torno da profissão docente foi bastante expressiva cerca de $10 \%$ do total (87), como exemplo, a matéria publicada em uma das capas do jornal com o comunicado da morte do professor Lindolfo Gomes, "notável jornalista, poeta, romancista", membro da Academia Mineira de Letras, uma representação bastante positiva de professor, termo destacado no título da notícia. 
Figura 01. Capa do Jornal O Repórter

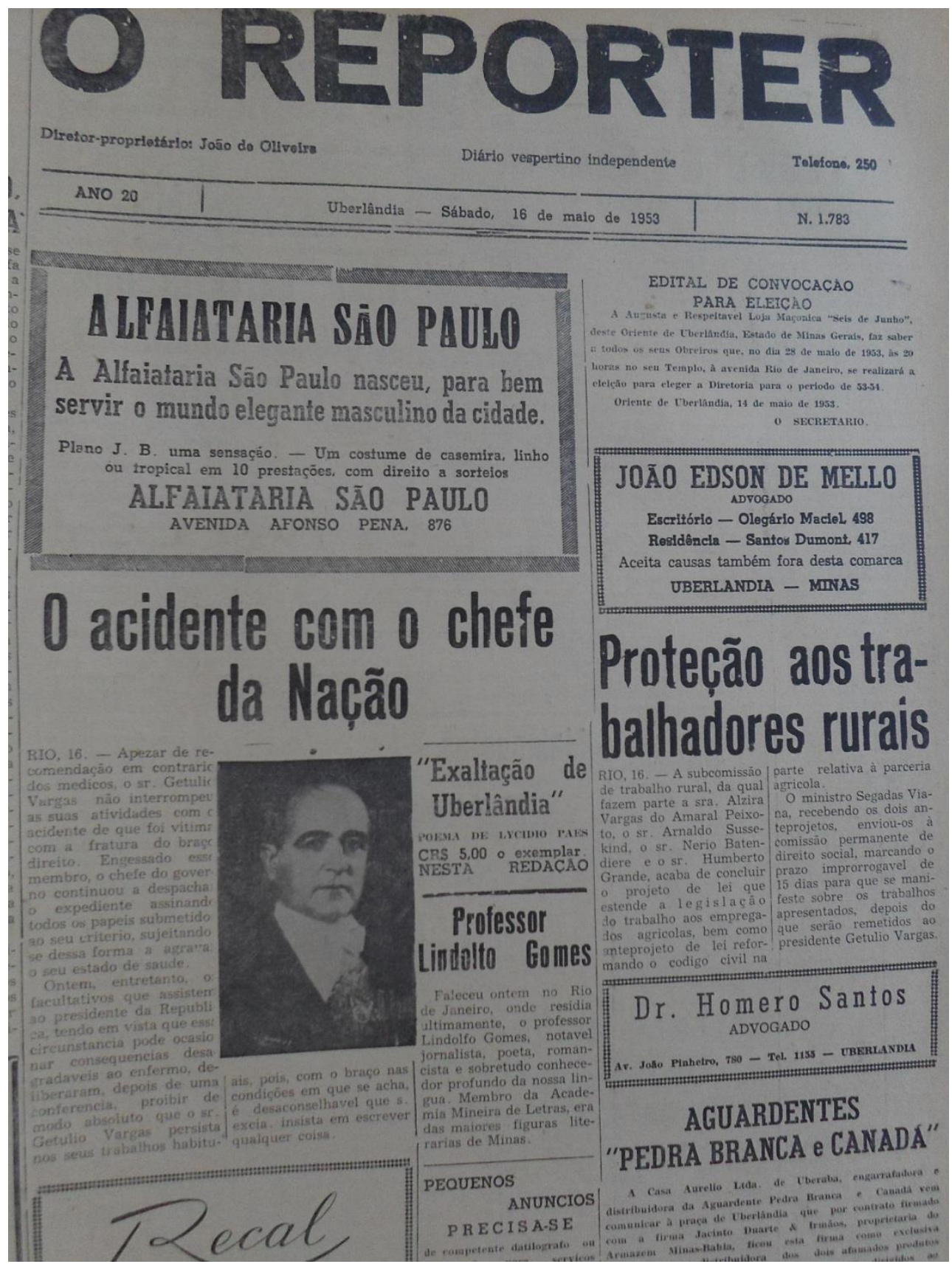

Fonte: Arquivo Público Municipal de Uberlândia. Coleção JOR, n.1783, 16/mai/1953.

O período recortado para estudo das representações relativas aos docentes neste jornal tem relação com o acelerado crescimento da rede pública escolar por todo o país e também em Uberlândia, e que pode ser percebido pelos intensos debates presentes em $O$ Repórter bem como nos demais jornais do Triângulo Mineiro (Franco, 2020). A expansão das oportunidades escolares esteve atrelada ao crescimento da urbanização que nesta região começou a ser impulsionado pela chegada da ferrovia ainda no século XIX (1872)ii que levou a emancipação de cidades (como São Pedro de Uberabinha, atual Uberlândia, no ano de 1888), mas o grande impulso a urbanização ocorreu com o advento da construção de Brasília, quando a região triangulina se transformou em rota para a grande obra do novo Distrito Federal. 
As notícias selecionadas para análise neste trabalho abordavam os termos professor (a), mestres ou educadores, de maneira que o conjunto analisado tratava de homenagens aos docentes (póstumas ou não), formação de professores (cursos de férias, palestras e visitas de personalidades nacionais e internacionais do campo da educação), a profissionalização da categoria (criação de associações, greves, aumento ou atraso nos salários), e aqueles que debatiam o papel da educação e do professor na sociedade, como o publicado com o título "Urge elevar e dignificar o professor" (JOR, 06/abril/1956). As reflexões alcançadas indicam que no processo de acelerado crescimento da rede escolar urbana do município mineiro, as representações dos professores eram apresentadas entre dois polos distintos muitas vezes como figuras de prestígio dignas de exaltação, mas também em alguns momentos acusados pela precariedade da educação em função da má formação.

Quanto a utilização do referencial das representações, consideramos adequado recorrer a Chartier (1990), o qual as considera como formas pelas quais determinadas comunidades buscam interpretar suas realidades, de acordo com seus próprios interesses. Logo essas representações são construídas na relação entre o ser e o parecer, de forma que:

\begin{abstract}
As representações do mundo social assim construídas, embora aspirem à universalidade de um diagnóstico fundado na razão, são sempre determinados pelos interesses de grupo que as forjam. Daí, para cada caso, o necessário relacionamento dos discursos proferidos com a posição de quem os utiliza. As percepções do social não são de forma alguma discursos neutros: produzem estratégias e práticas (sociais, escolares, políticas) que tendem a impor uma autoridade à custa de outros, por ela menosprezados, a legitimar um projeto reformador ou a justificar, para os próprios indivíduos, as suas escolhas e condutas (Chartier, 1990, p. 17).
\end{abstract}

Desse modo, entendemos que as representações de imprensa, assim como qualquer outra fonte de pesquisa histórica, não são nunca discursos neutros, pois apresentam linguagens que aspiram aos interesses e visões de mundo de certos grupos ligados a esses veículos de comunicação. Assim a análise das representações veiculadas por esse jornal local desvela o imaginário social e aspectos culturais que circulavam em determinados grupos presentes na sociedade uberlandense do período em questão.

A pesquisa na área de história da educação depara-se com dificuldades diversas, mas nenhuma é tão relevante quanto a que diz respeito ao acesso à documentação nas repartições públicas e unidades escolares. Uma das formas de superação deste obstáculo é a utilização de fontes como os jornais referentes à educação escolar, que podem colaborar para "identificar o modo como [...] uma determinada 'realidade' social é construída, pensada, dada a ler." (Chartier, 1990, p. 15).

\title{
Representações da Docência
}

Antes de observarmos as imagens produzidas pelo Jornal $O$ Repórter sobre a ideia da docência é preciso ressaltar que ao longo da história, a profissão docente foi objeto de disputas em diferentes esferas que tradicionalmente tem debatido o seu papel junto a sociedade, de forma que tais definições e redefinições conceituais sempre estiveram atreladas as mudanças ocorridas no campo de atuação profissional 
dos professores, envolvendo as diferentes dimensões da docência e a articulação da categoria dos docentes com as políticas de estado (NÓVOA, 1992).

$\mathrm{Na}$ trajetória da profissão muitos modelos de formação foram adotados no Brasil, em princípio, havia o predomínio das ordens religiosas católicas na formação de sacerdotes que assumiriam a educação mais ampla, deixando sua marca indelével nos processos constituintes da docência por séculos. Algumas mudanças surgiriam após as Reformas Pombalinas e a adoção das aulas régias, no entanto, a educação tradicional baseada na pedagogia mais expressiva da Ratio Studiorum (baseada na didática mnemônica) prevaleceria ainda por décadas, atravessando quase todo o século XIX quando as primeiras iniciativas no sentido de renovação da formação docente foram tomadas com a emergência das Escolas Normais (após a promulgação do Ato Institucional de 1834), mas que se consolidariam apenas décadas mais tarde, em decorrência das alterações do cenário político-administrativo do país que deixara a condição de colônia e passara a existir enquanto império (Xavier, 2014).

Dessa maneira, além das mudanças na formação do professor, a forma de recrutamento deles passou também por transformações significativas, deixando-se os concursos de nomeação que levavam em conta apenas o atestado de moralidade e conhecimentos do início do século XIX até chegar ao contexto de construção democrática que viabilizou a adoção do concurso público para ingresso no magistério, o que ajudou a fomentar as primeiras manifestações em favor de melhorias salariais e o associativismo docente a partir de fins do século XX (Xavier, 2014).

Destacamos ainda, que os anos de 1930 foram bastante importantes para a formação de professores em função da criação dos cursos de pedagogia nos Institutos de Educação que passaram a substituir pouco a pouco as Escolas Normais. Segundo Tanuri (2000), a formação do docente de nível primário acontecia ao longo de dois anos contendo as disciplinas de fundamentos e das metodologias de ensino. Assim, o curso de Pedagogia tinha entre seus objetivos iniciais a formação de professores para a Escola Normal e para os Institutos de Educação. O primeiro curso superior de formação de professores foi criado apenas em 1935, quando a Escola de Professores foi incorporada à Universidade do Distrito Federal. Esses institutos também ofertavam cursos de especialização, aperfeiçoamento, extensão e outros (Tanuri, 2000). E ainda nos anos de 1940, as leis orgânicas buscaram dar organicidade a educação em nível nacional, vejamos:

\begin{abstract}
A Lei Orgânica do Ensino Normal (1946) reforça a existência das escolas normais, diversifica-as com cursos específicos para a zona rural (escolas normais rurais) e cria os Institutos de Educação, que, além do curso normal, deveriam também oferecer formação superior e continuada aos professores primários (Freitas, 2015, p. 08-09).
\end{abstract}

Ainda é necessário destacar que foi ao longo das décadas de 1950 e 1960 que os docentes se apresentaram no cenário social enquanto trabalhadores da educação, promovendo uma nova imagem da profissão, que ganhava em profissionalismo e politização atuando na esfera pública em defesa de seus interesses de categoria profissional. Foi neste momento que se multiplicaram os sindicatos, já que urgia enfrentar os desmandos das diferentes esferas de governo em busca de sua valorização (Vicentini, Lugli, 2009).

É possível observar pelas reportagens presentes em O Repórter que essa imagem foi construída apoiada em algumas variáveis debatidas em suas matérias no período analisado, em especial destacamos o processo de formação dos professores, as instituições onde atuavam, o seu nível de conhecimento, as condições de exercício 
da docência e a organização em entidades profissionais, entre outras questões observadas no processo de profissionalização da profissão professor. É claro que toda generalização nesse caso, torna-se arbitrária em função da diversidade de fatos vividos em cada época e das características de cada grupo social em seus contextos específicos que moldaram as diferentes experiências educativas nesse país.

Feitas as observações sobre alguns dos marcos da profissão docente no Brasil, podemos passar a análise das representações de professor, mestre e educador presentes no jornal $O$ Repórter. Assim, identificamos no olhar desse jornal alguns dos sentidos construídos sobre a profissão docente por meio das notícias, destacamos alguns temas principais: homenagens a professores (póstumas ou não), formação docente (cursos de férias, congressos, seminários, treinamentos, palestras e visitas de personalidades da área da educação), reivindicações (criação de associações, greves, aumento ou atraso nos salários), internacionalização do professorado brasileiro, alfabetização de adultos, ensino primário e secundário, bem como discursos que procuravam teorizar o papel da educação e do professor. analisado:

Este conjunto de 87 notícias estava distribuído da seguinte forma no período

Quadro 01. Relação de Notícias sobre "profissão docente" - Jornal O Repórter (1950 - 1963)

\begin{tabular}{|l|c|c|c|c|c|c|c|c|c|c|c|}
\hline Ano/Nível & $\mathbf{1 9 5 0}$ & $\mathbf{1 9 5 3}$ & $\mathbf{1 9 5 4}$ & $\mathbf{1 9 5 5}$ & $\mathbf{1 9 5 6}$ & $\mathbf{1 9 5 9}$ & $\mathbf{1 9 6 0}$ & $\mathbf{1 9 6 1}$ & $\mathbf{1 9 6 2}$ & $\mathbf{1 9 6 3}$ & Total \\
\hline EJA & 1 & & & & & & 1 & & 1 & & 3 \\
\hline Primário & & 5 & 2 & & & 1 & 3 & & 1 & & 12 \\
\hline Secundário & & 5 & & & 2 & & 2 & & 2 & & 11 \\
\hline Técnico & & & & & & & & & 1 & & 1 \\
\hline Superior & & 1 & & 3 & 1 & & 6 & 5 & 4 & 1 & 21 \\
\hline Diversos & & 1 & & & 3 & & 1 & & 1 & 1 & 7 \\
\hline Outros & & 6 & 4 & 6 & 6 & 6 & 1 & 1 & 2 & & 32 \\
\hline Total & 1 & 18 & 6 & 9 & 12 & 7 & 14 & 6 & 12 & 2 & 87 \\
\hline
\end{tabular}

Fonte: Arquivo Público Municipal de Uberlândia. Coleção JOR (1950-1963).

Das notícias referentes à profissão docente, 32 (37\% do total) estão relacionadas aos ensinos médio e superior, revelando certo caráter elitista do jornal já que estes níveis educacionais atendiam a pequena parcela da população naquele período, bem como o interesse desse veículo em debater questões relativas a seu público anunciante e leitor.

É possível observar pelo conjunto das reportagens que predominava entre elas a valorização da figura do professor, como podemos destacar em algumas delas, que veiculavam o ato de gratidão aos mestres por parte dos alunos, tal como: "Carta de um aluno a um de seus mestres";

É para mim grande prazer falar-lhe esse tema, que muito me agrada. Sendo o Português uma das matérias que mais aprecio, as aulas que a Sra. tão bondosamente, nos dá são recebidas com maior boa vontade possível. Apesar do pouco que sei, admiro suas aulas, assim como a tática que a Sra. emprega para aumentar nossos conhecimentos (JOR, 25/ago/1956). 
Vemos um exemplo de honraria a uma docente, de como a imprensa local vinculava a representação positiva da docência à figura do mestre e seu trabalho bondoso e admirável, era comum e valorizado nos espaços escolares, tais imagens eram bastante presentes no jornal, em especial, nos eventos de formatura escolares, comemorações do dia dos professores, e homenagens a docentes aposentados ou falecidos.

A imagem do mestre vinculada à docência também surge relacionada a nobre missão da alfabetização mesmo na Educação de Jovens e Adultos: "Mestres para alfabetizar adultos" (JOR, 07/fev/1962), é preciso ressaltar contudo, que em todo período pesquisado foram registradas apenas 3 notícias que abordavam esse tipo de educação.

\begin{abstract}
"Mestres para alfabetizar adultos" - Todos os professores e professoras que se considerem em condições de reger, ou continuar a reger, no seu município, classes noturnas de ensino primário supletivo a ser instaladas no corrente ano, mediante acordo entre o governo estadual ou municipal e Ministério da Educação e Cultura, queiram enviar à Campana de Educação de Adultos - Palácio da Cultura, sala 1404, Rio de Janeiro, até o dia 15 de fevereiro e seu curriculum vitae, contendo a indicação de atestado, certificados ou diplomas de conclusão de curso ou de tirocínio de magistério. Os cursos serão de meses, percebendo o regente em cada um dos sete meses a remuneração pro labore de Cr\$3.000,00 sem prejuízo de exercício de qualquer outra função pública particular, desde que haja compatibilidade de horário (JOR, 07/mar/1962).
\end{abstract}

Nesta reportagem, a ideia de mestre era associada a tarefa nobre da alfabetização, que para tal, seria necessário o tirocínio ou a iniciação/experiência no magistério, pois tal tarefa, seria entre as mais importantes na luta contra 0 analfabetismo e elevar os níveis culturais do povo:

\begin{abstract}
"Oitocentos mestres já treinados para erradicar o analfabetismo" - Falando à imprensa, o professor João Roberto Moreira, coordenador da Campanha Nacional de Erradicação do Analfabetismo, do Departamento Nacional de Educação, informou que para as tarefas do ensino no meio rural, sua repartição já treinou, através de seminários e cursos especiais, quatrocentos e vinte professores. Os resultados dessa iniciativa são os mais auspiciosos que se poderia esperar, dando ao trabalho um cunho eminentemente seguro ao plano de ação e a certeza de que o ministro Clovis Salgado esclareceu ser a campanha a única solução para resolver este angustiante problema de elevação dos níveis culturais do povo. No momento, ressaltou o professor Moreira, realiza o CNEA, uma operação de grande envergadura, concentrando trezentas e cinquenta mestras, em estágio cujo final está próximo. Todas elas serão lançadas imediatamente no programa que está em curso em dez municípios de regiões variadas, escolhidos como centros experimentais para a explicação das novas técnicas didáticas, com vistas à extinção do analfabetismo. $\mathrm{O}$ alvo é um só: escolarização em massa, da infância que vive no interior e, principalmente, no meio rural, onde dificuldades diversas estão sendo vencidas com novos instrumentos de ação $(23 / \mathrm{mar} / 1960)$.
\end{abstract}

Nestas reportagens, o jornal falava sobre a necessidade de formação de professores especializados na nobre tarefa de alfabetização de adultos. É importante lembrar que no início dos anos de 1960, havia um esforço da sociedade civil e política no sentido de se alfabetizar as massas, buscando não apenas a instrução, mas a educação política, exemplos desse processo foram os movimentos "De pé no chão também se aprende a ler" implantada pelo prefeito de Natal-RN (Djalma Maranhão) e 
"Quarenta horas de Angicos" experiência coordenada por Paulo Freire (Cunha; Goes, 1989).

Outro aspecto que se pode em torno da imagem da docência é a ideia de que seria uma atividade ligada a missão e ao sacrifício pessoal, associada aos outros níveis de ensino como o primário. Pela notícia que segue a imagem da professora primária, que eram "obrigadas" a estagiarem em zonas distantes das cidades, acabariam por se apegar ao seu martírio pessoal, em nome do "relevante papel na educação das crianças":

As professoras que exercem atividades nas Escolas Rurais do Estado da Guanabara vem desempenhando relevante papel na educação das crianças do chamado "cinturião verde" da nova unidade da Federação. Obrigadas ao estágio de um ano naquela área, identificam-se de tal modo, como o meio que, na maioria, não pretendem transferir-se para os estabelecimentos da zona urbana (JOR, 09/jul/1960).

No início dos anos de 1950, as professoras do munícipio de Uberlândia também eram chamadas a prestarem seu sacrifício em nome da docência como mostra a reportagem que relatava o atraso no pagamento de seus salários: "Professoras Municipais de Uberaba não recebem os vencimentos - Desde fevereiro deste ano as professoras primárias municipais não recebem seus vencimentos embora protestem com veemência ninguém toma conhecimento da angustiante situação das professoras (JOR, 09/nov/1954)".

Quanto à representação do professor que atuava nos ensinos secundário e superior, prevalecia nas matérias do jornal o reconhecimento pelo seu importante trabalho, reforçando-se certa hierarquia em relação ao ensino primário. Vejamos a matéria que segue: "50 milhões de dólares para professores universitários" (JOR, 21/mar/1955), nesta reportagem, apontava-se que a Fundação Ford estabeleceu um fundo em dólar para recompensar os professores universitários que não receberiam rendimentos suficientes.

Outro aspecto presente nas notícias em relação ao ensino superior era a quase padronização do discurso jornalístico que refletia o pensamento das classes dominantes de que esse nível de educação expressaria o desenvolvimento e 0 progresso local, como a notícia celebrada da doação de recursos para complementar os salários de professores universitários pela Fundação Ford. A reportagem intitulada "Falta de quatrocentos mestres" (JOR, 13/jan/1961) se referia a falta de professores para trabalhar o ensino de Economia no Brasil, associando a docência de nível superior à imagem do mestre.

Em muitos momentos a imprensa denunciava também os problemas desses níveis de ensino, como descrito na notícia intitulada "Os professores do Colégio Estadual não recebem desde março", problema relativo a uma instituição que também ofertava o ensino secundário, vejamos:

Desde o início do período escolar, isto é, 1ำ de março, não recebem os professores do Colégio Estadual, um centavo sequer. Como se vê, o governo estadual relegou a plano secundaríssimo, a missão dos homens que tem sobre os ombros o encargo de educar essa juventude. A situação é por demais inconcebível, pois os professores daquele estabelecimento já se veem frente a problemas de ordem financeira agravados que 0 próprio crédito vai desaparecendo (JOR, 13/out/1956). 
O Colégio Estadual foi criado em 03 de janeiro de 1929 como Ginásio Mineiro de Uberabinha, um estabelecimento oficial de ensino público na cidade da atual Uberlândia-MG. De acordo com Machado e Gatti Jr (2002, p. 36): "O curso Ginasial foi restringido a quatro anos em 1944, nos moldes da reforma do ensino secundário e criou-se o Curso Colegial, Com mais três anos; este último funcionando também à noite em 1950."

Figura 02. Reportagem Jornal O Repórter

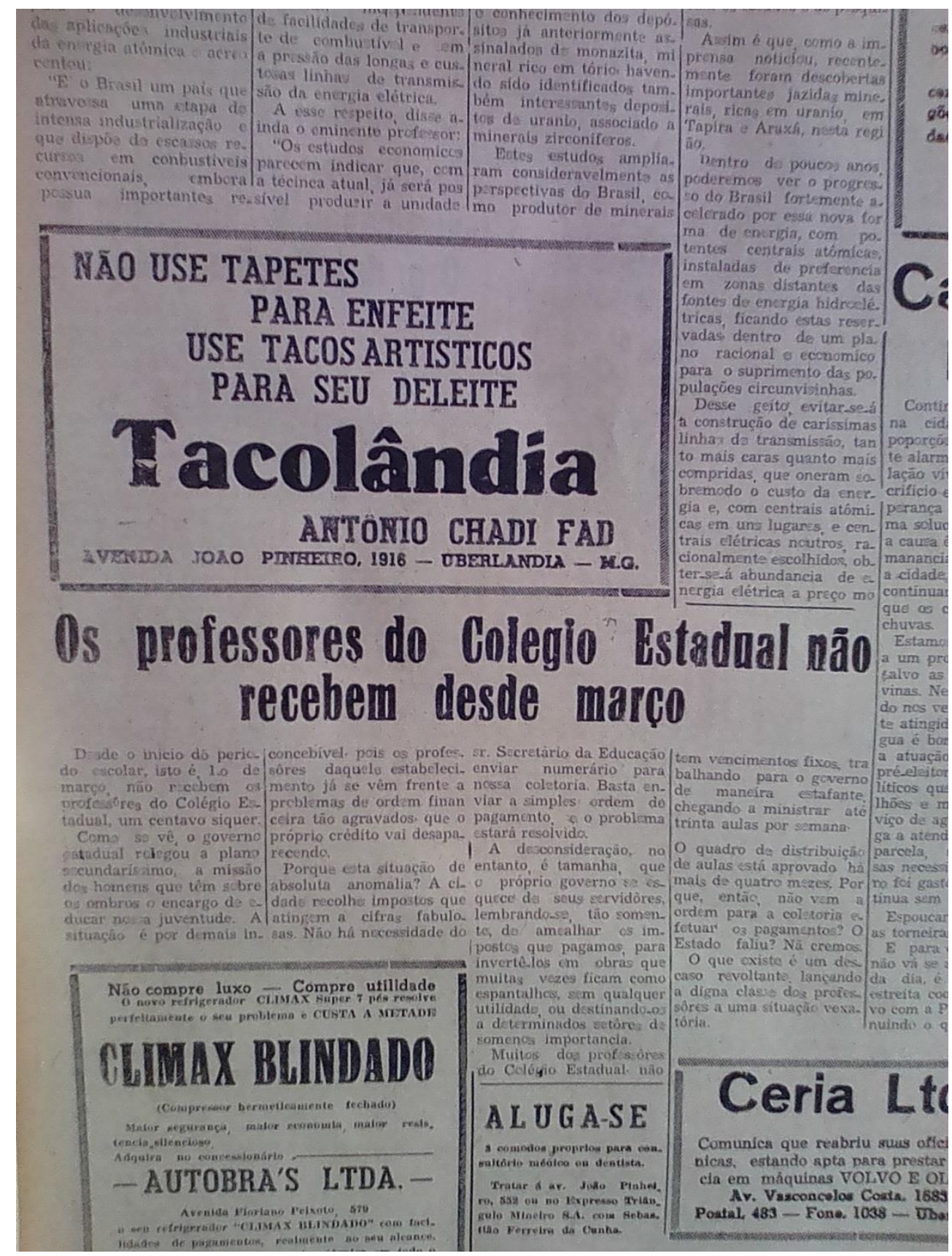

Fonte: Arquivo Público Municipal de Uberlândia. Coleção JOR, n.2587, 13/out/1956.

Como é possível observar, a reportagem alertava para uma situação absurda, a falta de salários em quase todo o ano letivo, o articulista mais uma vez vinculava a docência a "missão dos homens que tem sobre os ombros o encargo de educar", 
dessa forma, a ideia de sacrifício do docente surgia novamente nas páginas desse jornal de Uberlândia.

Apesar de prevalecer a representação da figura do mestre condutor da juventude e exemplo para as futuras gerações, especialmente ao longo dos anos de 1950 , essa imagem começa a ser alterada quando vista nas páginas do Jornal $O$ Repórter no início da década seguinte, assim, destacamos algumas delas como o relato das primeiras greves da categoria "Professores paulistas declaram greve - 0 magistério primário e secundário oficial do Estado de São Paulo entrou em greve ao primeiro minuto de hoje por tempo indeterminado, reivindicando melhores níveis de vencimento (JOR, 17/out/1963)". E a ideia de classe profissional ia aos poucos se consolidando via associações como se pode na reportagem que segue convidando a categoria para uma reunião cujo objetivo era a construção de uma associação para os professores secundaristas da cidade:

\footnotetext{
"Associação de professores secundários" - Realizou-se domingo, dia 13, às 15 horas, no Colégio Estadual de Uberlândia, uma reunião de professores, com a finalidade de constituir a Associação de Professores Secundários de Uberlândia. Nessa reunião, foi eleita uma comissão organizadora provisória (que presidirá aos trabalhos até a eleição da Diretoria em Assembléia Geral) [...] A Associação de Professores Secundários de Uberlândia tem um vasto programa de realizações. Suas atividades serão iniciadas por uma conferência sobre Literatura Mineira, a cargo do Prof. Eurico Silva, que gentilmente acendeu ao convite da comissão organizadora. Oportunamente será publicado dia e local marcado para esta brilhante palestra literária. Desde já, convida-se todo o povo uberlandense. Aos Professores Secundários, a comissão faz um apelo para que compareçam à próxima reunião, marcada para domingo, dia 19, às 14 horas, no Colégio Estadual de Uberlândia (JOR, 19/mar/1960).
}

Além dessas notícias vinculadas a profissionalização docente, surgia também a precarização das condições de trabalho com a ampliação do número de professores em todos os níveis educativos: "Professora espancada em pleno exercício do poder" (JOR, 30/abr/1962). Essa última notícia revela que a profissão professor começava a perder seu status junto a sociedade a medida que a categoria era massificada atendendo a um público mais amplo e diverso, além da precarização do seu trabalho, vejamos:

\begin{abstract}
A professora municipal Eleusa Lozzi de Oliveira da Escola Fé e Amor, foi agredida brutalmente pela mãe de um dos seus alunos, pelo simples fato de manter ordem no educandário, não permitindo entrar fora do horário regulamentar (JOR, 30/jul/1962).
\end{abstract}

O fato narrado evidencia que, muito embora, havia a veiculação predominante de uma imagem positiva em torno da representação do professor por parte do Jornal O Repórter, observa-se que já nos anos 1960 as vicissitudes da profissão professor começavam a disputar esse espaço jornalístico com a imagem de ofício prestigiado que envolvia a docência, até então. Assim, o glamour em torno dos mestres começava a perder espaço a medida que a profissão docente se massificava no Brasil, acompanhada pelo multiplicação dos problemas decorrentes da acelerada expansão pouco planejada.

Outra reportagem que pode demonstrar as dificuldades da profissão é a que trata da reprovação de professores em processo seletivo para o exercício do magistério realizado em Uberaba. Vejamos: 
Dos 300 candidatos, apenas 75 foram aprovados nos exames: os demais, por um ou outro motivo, formam desaconselhados de se submeterem às provas finais, devendo esperar melhor oportunidade para obtenção do certificado de professores secundaristas (JOR, 18/fev/1959).

A notícia retratava um processo seletivo feito na cidade vizinha de UberlândiaMG, do qual a maioria dos professores havia sido reprovada. Nota-se que na representação da docência quanto a algum tipo de fracasso, vinculação a movimentos sociais, escassez de recursos, o termo utilizado era sempre o de professor. Do outro lado, quando o caráter da notícia eram homenagens, grandes feitos, palestras e honrarias o termo predominante era mestre ou educador(a): "Homenageada pelos alunos do Liceu ilustre educadora uberlandense" (JOR, 19/mai/1953) e ainda: "Carta de um aluno a um de seus mestres" (JOR, 25/ago/1956), indicando alguma hierarquização semântica.

Outro detalhe é que, mesmo que houvesse algo negativo associado à profissão, era exposta de forma sutil, de modo a não subtrair o valor social que tinham os professores, mestres e educadores no período, até porque se deve considerar que no caso desse jornal, um dos seus editores era Eurico Silva que também atuava como professor, o que contribuía para a exaltação da sua categoria, uma ação corporativa. "Prof. Eurico Silva" - Procedente de Campinas, São Paulo, onde estivera em gôzo de merecidas férias e reestabelecido do acidente de que fora vítima, regressou a esta cidade o sr. Prof. Eurico Silva, emérito homem de letras, lente do Colégio Estadual de Uberlândia e nosso apreciado colaborador (JOR, 11/ago/1953).

Outro tema importante de abordar no conjunto de notícias selecionadas é a ideia de internacionalização dos professores brasileiros presente no jornal O Repórter, esse tipo de fala projetava o que era de fora enquanto algo positivo, digno de ser copiado, seja por meio de treinamentos, seminários ou intercâmbios. Vejamos: "Professores brasileiros" (JOR, 25/jul/1955) relatando a presença de docentes brasileiros em curso de aperfeiçoamento em Londres e a "Educadores" (JOR, 03/jul/1959) falando do intercâmbio de professores brasileiros nos EUA:

\footnotetext{
"Educadores" - O número de professores brasileiros que se encontra atualmente nos Estados Unidos é, realmente excepcional. Neste momento, cerca de 20 educadores nossos acham-se em território norte-americano. Alguns lá estão a convite das autoridades educacionais daquele país. [...] a presença de brasileiros é parte de extenso programa de intercâmbio cultural entre os dois países. Pelo menos a presença daqueles que lá estão como convidados de alguma organização particular ou oficial dos Estados Unidos. O intercambio Cultural é orientado, basicamente, pelo Serviço Internacional de Intercâmbio Educativo do Departamento de Estado [...] (JOR, 07/nov/1959).
}

E ainda: "UCBEU promoverá seminário de um dia para professores de inglês" (JOR, 22/nov/1962): A União Cultural Brasil-Estados Unidos de São Paulo vai realizar sábado próximo dia 24 , um seminário para professores de inglês - mas que poderá ser assistido também por demais pessoas interessadas - que versará sobre 0 elemento "far West" na cultura norte-americana (JOR, 22/nov/1962). "Intercâmbios de estágios entre mestres lusos e brasileiros" (JOR, 26/jan/1961) que abordava as iniciativas dos governos brasileiro e português para promover troca de experiências aprofundamento teórico/prático aos professores de Educação Física: 
Figura 03. Reportagem Jornal O Repórter

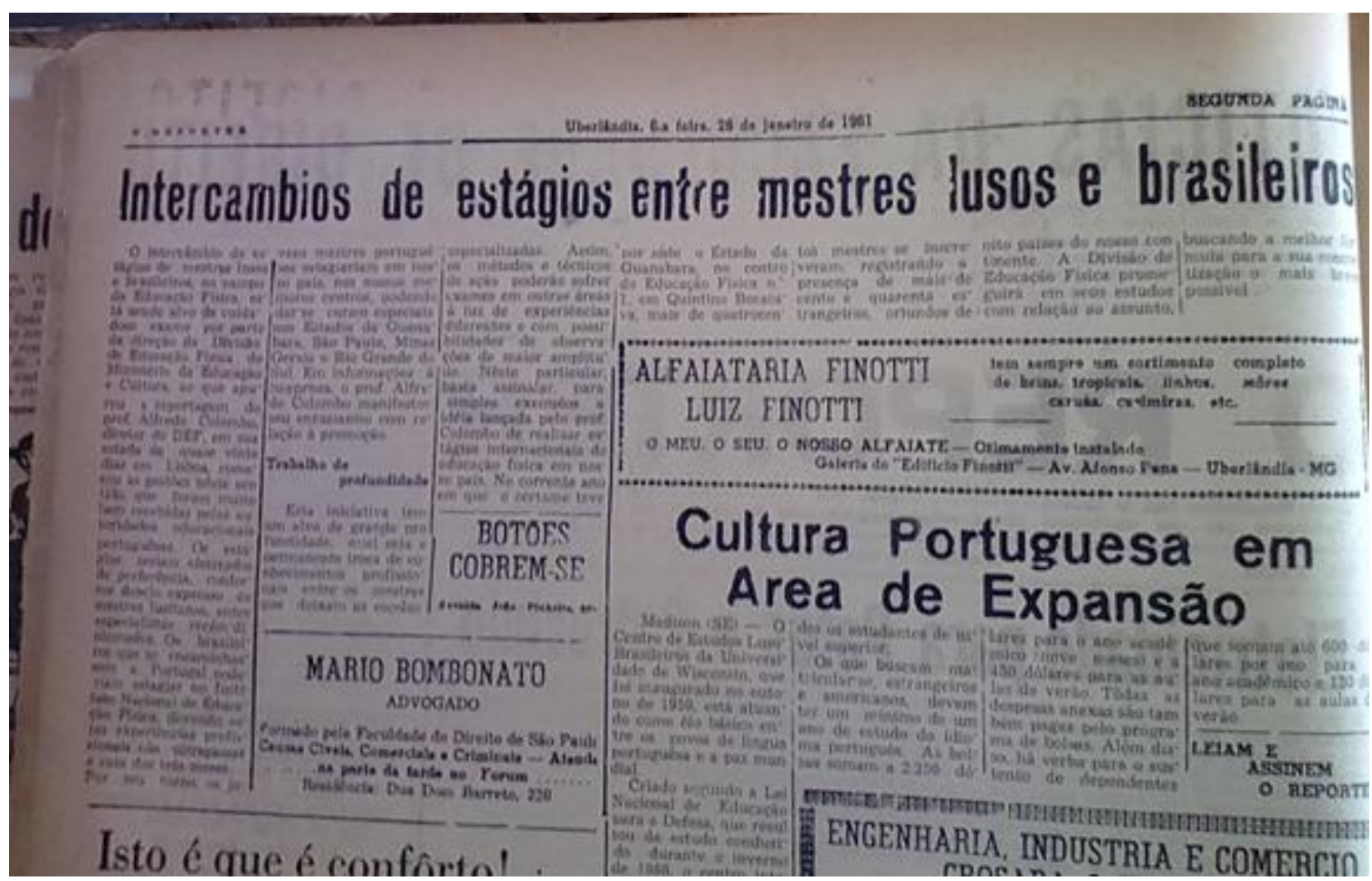

Fonte: Arquivo Público Municipal de Uberlândia. Coleção JOR, 26/jan/1961.

O jornal procurava com tal preocupação, reforçar a ideia de que os países desenvolvidos deviam ser copiados em suas experiências educativas, mas também fomentar o interesse pela profissão docente, divulgando iniciativas do Estado em proporcionar uma formação diferenciada aos professores, com intercâmbios internacionais, buscando atrair quadros para uma profissão que ainda tinha carências de mão de obra. O número de professores da educação primária passou de 284 mil em 1960 para 654 mil em 1970, um crescimento da categoria de 130\% em apenas 10 anos. (INEP, 2019).

O maior número de notícias sobre a profissão docente está na categoria "Outros" com um total de 32, demonstrando grande diversificação dos temas relativos a docência em geral e não vinculada a um nível de ensino específico, como exemplo: "Prof. Roquete Pinto - Falecimento do professor" (JOR, 19/out/1954): "Faleceu na tarde do dia 18 em Petrópolis o prof. Edgard Roquete Pinto, um dos pioneiros do rádio brasileiro, grande mestre e educador patrício, escritor de renome, membro da Academia Brasileira de Letras (19/10/1954)." E também informativos, como a chegada de um professor da Universidade do Brasil à Uberlândia, intitulada: "Professor Eduardo Lopes Rodrigues" (JOR, 22/out/1960): "A cidade hospeda desde ontem o ilustre professor Eduardo Lopes Rodrigues da Universidade do Brasil, que aqui se encontra a convite da Faculdade de Direito de Uberlândia, para conferir nas noites de 24 a 27 de outubro corrente, conferências no curso de Extensão Tributária, e designado pelo ilustre o Diretor do Imposto de Renda, Dr. Jorge Veloso Padilha que assim empresta valiosa cooperação ao nosso movimento cultural (JOR, 22/out/1960)."; "Homenagem póstuma ao professor Henckmar Borges":

A Câmara Municipal de Uberlândia aprovou projeto para colocação de uma fotografia do saudoso professor e ex-vereador Henckmar Borges no recinto de sua sala de sessões. A cerimônia de exposição da fotografia terá lugar na noite de amanhã. (JOR, 05/jan/1955). 
Tais notícias sobre o cotidiano de algumas figuras públicas ligadas a docência ganhavam destaque nas páginas do Jornal $O$ Repórter, incrementando o capital político desses professores que em alguns casos se lançavam à vida política a partir da popularidade adquirida nas funções cotidianas no universo educacional.

\section{Considerações Finais}

Por fim, reforçamos uma vez mais o objetivo da pesquisa em torno do interesse em debater as representações de imprensa construídas em torno da ideia de professor(a), mestre e educador pelo Jornal O Repórter revelando o jogo de interesses em torno dessas concepções difundidas, demonstrando que a disputa em torno do perfil da docência fora bastante acirrada nesse período, e também nas cidades do interior do país, como Uberlândia-MG. Uma das matérias sintomáticas desse debate foi a "Urge elevar e dignificar o professor" (JOR, 06/abr/1956) onde se debatia um plano de educação para o Brasil, cuja meta deveria ser o desenvolvimento da nação a partir da criação de um "Fundo Escolar" buscando melhorar todos os níveis dos ensinos público e privado, considerando "indispensável [...] a iniciativa privada". Em relação a necessidade de se valorizar o professor, a matéria jornalística vinculava essa tarefa a formação inicial:

Ensino Normal - Ponto excepcional de renovação pedagógica. É preciso haver um corpo de professores para todas as categorias de ensino. O primeiro passo é a escola normal, desde a primária a superior. Remunerado convenientemente o professor fara de sua escola o objetivo exclusivo de suas preocupações práticas. (JOR, 06/jul/1956).

Figura 04. Reportagem Jornal O Repórter

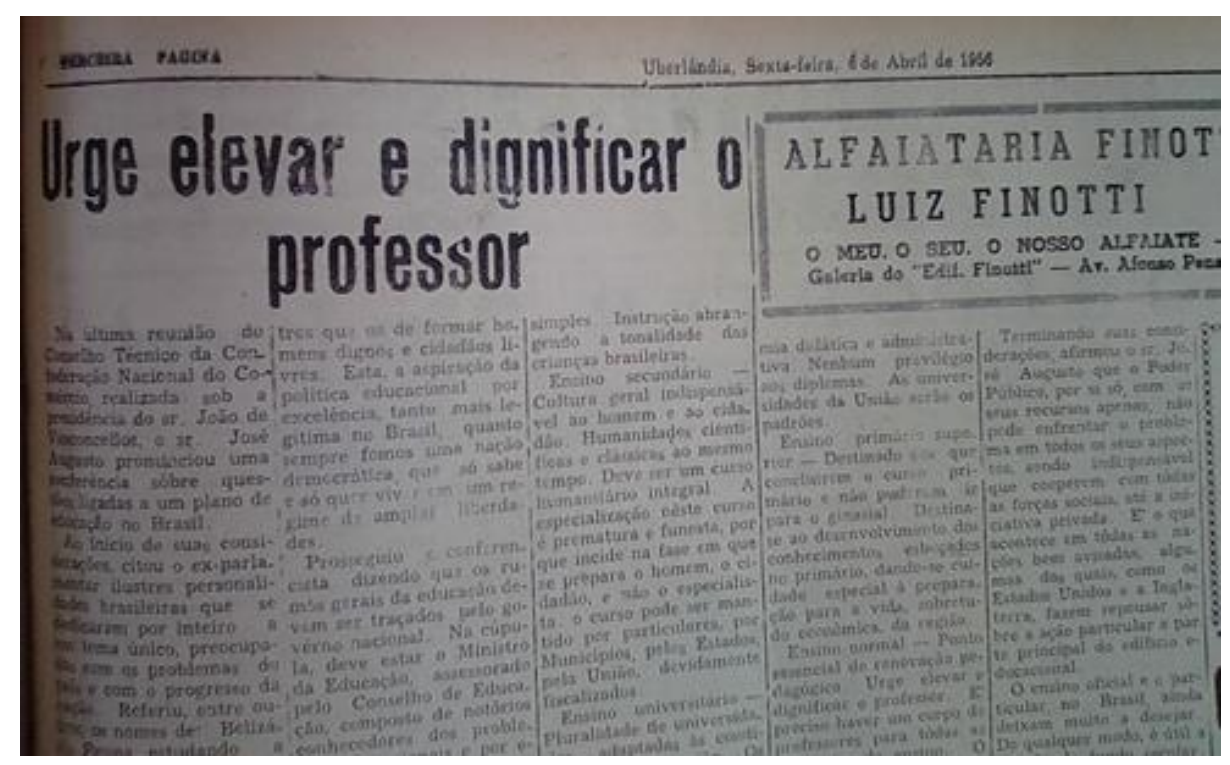

Fonte: Arquivo Público Municipal de Uberlândia. Coleção JOR, 06/jul/1956.

Assim, as análises e reflexões feitas aqui mostram que no processo de crescimento da rede escolar urbana de Uberlândia, as representações sobre ideia e 
ideal de professor/a eram apresentadas entre dois polos distintos: muitas vezes como figuras de prestígio dignas de exaltação, mas também, de forma sutil, eram apresentadas as dificuldades e fragilidades do trabalho docente em função da má formação e condições de trabalho, representação que se consolidava a medida em que a profissão docente se avolumava no cenário urbano, especialmente, a partir de fins dos anos de 1950.

A variedade de temas envolvendo o professorado é grande e suficiente para identificarmos o olhar do periódico sobre diferentes perspectivas a respeito da profissão docente. O professor é visto de muitas formas, mas em síntese, percebemos que sua representação, apesar de suas várias facetas, é predominante sobre a imagem do herói ou missionário capaz de tudo realizar pelo bem de seus alunos, mesmo com todas as dificuldades apresentadas em boa parte das notícias.

\section{Referências}

Bugelli, Alexandre Hamilton. (2008). A crise econômica brasileira dos anos 1960: uma reconstrução do debate. 2008. 178 f. Dissertação (Mestrado em Economia) Pontifícia Universidade Católica de São Paulo, São Paulo.

Cunha, Luis Antônio; Góes, Moacyr de. (1989). O golpe na educação. 6. ed. Rio de Janeiro: Jorge Zarar Editor.

Dantas, S. M. (2017). Três cidades, um projeto: a modernidade no Triângulo Mineiro. Territórios e Fronteiras, 10(2), 212-232.

Franco, Isaura Melo. (2020). A Juventude Estudantil pelo olhar dos jornais do Triângulo Mineiro: entre a tutela e a subversão (décadas de 1950 e 1960). Tese de Doutorado em Educação, Universidade Federal de Uberlândia.

Freitas, Anamaria Gonçalves Bueno de. (2015). Formação de professores: demandas do passado e desafios do presente. Pensar a Educação em Revista, Curitiba/Belo Horizonte, 1(3), 5-19, out-dez.

Luca, Tânia Regina de. (2006). História dos, nos e por meio dos periódicos: trajetórias e perspectivas analíticas. In: Pinsky, Carla. (Org.). Fontes Históricas. São Paulo: Contexto.

Machado, Flavio; Gatti Junior, Décio. A Escola Estadual de Uberlândia: Anotações de Pesquisa. Cadernos de História da Educação, 1(1). jan./dez.

Nóvoa, A. (1992). Notas sobre formação (contínua) de professores. [S.I: s.ed.], 1992. (Mimeografado).

Souza, Sauloéber T.; Silveira, Daiane de Lima Soares. (2020) Vidas escolares entrecruzadas por itinerários migratórios: cultura e identidade de nordestinos no triângulo mineiro. Revista Perspectiva, Florianópolis, 38(4), 01-24, out./dez.

Vicentini, Paula Perin; Lugli, Rosário Genta. (2009). História da Profissão Docente no Brasil: representações em disputa. São Paulo: Cortez Editora.

Tanuri, Leonor. (2000). História da formação de professores. In: Saviani, Dermeval; Cunha, Luiz Antonio; Carvalho, Marta Maria Chagas de. 500 anos de educação escolar. São Paulo: ANPED/Autores Associados.

Xavier, L. N. (2014). A construção social e histórica da profissão docente uma síntese necessária. Revista Brasileira de Educação, 19, 827-849. 


\section{Notas}

'O projeto contou com o apoio da FAPEMIG que financiou o mesmo com a concessão de 12 meses de
bolsa de IC para que se pudesse desenvolver a primeira parte do levantamento de dados da pesquisa
junto ao Arquivo Municipal de Uberlândia-MG, resultando na catalogação e digitalização de 846
matérias do jornal "O Repórter" no período de 1950 a 1963 quando esse veículo deixou de circular na
cidade de Uberlândia. A segunda etapa o foco foi o Jornal "Correio de Uberlândia", cujos resultados
parciais $\quad$ já parciais já foram $\quad$ publicados,
https://ojs.franca.unesp.br/index.php/historiaecultura/article/view/2976.

ii Segundo Dantas (2017, p.214): "A ferrovia chegou ao Triângulo Mineiro pela Companhia Mogiana de Estradas de Ferro, nascida em 1872, por iniciativa de um grupo de fazendeiros paulistas, para escoar a produção cafeeira. Inicialmente na província de São Paulo, a Companhia recebeu concessão para expandir seus trilhos por Minas Gerais e Goiás. Em 1889, os trilhos ferroviários foram inaugurados em Uberaba, seis anos depois em Uberabinha e, no ano seguinte, em Araguari."

iii De acordo com Souza e Silveira (2020, p. 08): "Na nova capital federal, o trabalho na construção civil atraiu muitos migrantes nordestinos; contudo, parte desses indivíduos, utilizando-se da nova rota migratória, seguiram também para as lavouras do Triângulo Mineiro, atividade com que estavam familiarizados." 